\title{
Políticas públicas para a educação infantil no Brasil: desafios à consolidação do direito no contexto emergente da nova filantropia
}

\author{
Public policies for early childhood education in Brazil: challenges to the \\ consolidation of the law in the emerging context of new philanthropy
}

\section{Políticas públicas para la educación infantil en Brasil: desafíos para la consolidación del derecho en el contexto emergente de la nueva filantropia}

\author{
Maria Luiza Flores ${ }^{1}$ \\ Universidade Federal do Rio Grande do Sul, Professora Adjunta do Departamento de Estudos \\ Especializados da Faculdade de Educação
}

Vera Maria Vidal Peroni ${ }^{2}$

Universidade Federal do Rio Grande do Sul, Professora nos cursos de graduação e pósgraduação em educação

Resumo: No texto analisam-se avanços e tensões no campo das políticas públicas educacionais no sentido da efetivação do direito à educação infantil no Brasil. A avaliação da trajetória dessa etapa educacional de 1996 até os dias atuais evidencia a consolidação de um conjunto normativo regulador que não garantiu acesso e qualidade para todos. Argumentamos que a concepção de educação infantil presente nos dispositivos legais ainda não se materializou plenamente em políticas públicas garantidoras desse direito educacional, estando, de fato, fortemente ameaçada por modelos privatistas caracterizados como uma nova filantropia, constituída de investidores sociais privados organizados em institutos e fundações que defendem investimentos na primeira infância com argumentos economicistas.

Palavras-chave: Educação infantil. Políticas educacionais. Organismos multilaterais. Privatização. Qualidade.

Abstract: The article analyzes the advances and tensions in the field of educational policies towards the consolidation of the right to early childhood education in Bra-

Mestre e Doutora em Educação pela Universidade Federal do Rio Grande do Sul.

2 Doutora em Educação: História, Política, Sociedade pela Pontifícia Universidade Católica de São Paulo; Mestrado em Educação pela Universidade Federal de Mato Grosso do Sul. 
zil. The evaluation of the history of this educational stage from 1996 to the present shows the consolidation of a regulatory body of norms that did not guarantee access and quality. Such evidence supports an argument that the concept of early childhood education that guidance the law are not materialized in public policies that should guarantee this educational right. These conception is, in fact, strongly threatened by privatist models characterized as a new philanthropy, made up of private social investors organized in institutes and foundations that argue about investments in early childhood based on econometric reasons.

Keywords: Early childhood education. Educational policy. Multilateral organizations. Privatization. Quality.

Resumen: Este artículo analiza los avances y las tensiones en el campo de las políticas públicas en el sentido del cumplimiento del derecho a la educación infantil en Brasil. La evaluación de la trayectoria de esta etapa educativa de 1996 hasta la actualidad demuestra la consolidación de un conjunto de reglas que no ha asegurado el acceso y la calidad. Nuestro argumento es que la concepción de educación infantil presente en los dispositivos legales no se ha materializado en las politicas públicas, y es, de hecho, fuertemente amenazada por modelos privatizadores caracterizados como una nueva filantropía, constituida por inversores sociales privados organizados en los institutos y fundaciones que apoyan las inversiones en la primera infancia con argumentos economicistas.

Palabras clave: Educación infantil. Políticas educativas. Organismos multilaterales. Privatización. Calidad.

\section{INTRODUÇÃO}

Nosso objetivo neste estudo é analisar os avanços e as tensões no campo das políticas públicas educacionais nas últimas décadas no sentido da efetivação do direito à educação infantil no Brasil, não apenas no que se refere à expansão de matrículas, mas, também, em relação aos aspectos inerentes à qualidade desta oferta (BRASIL, 2009a, 2009b, 2009c, 2015). Argumentamos que existem diferentes projetos em disputa em termos de concepção de educação infantil, global e localmente, o que exige a análise de um contexto amplo e complexo no qual, a despeito do ordenamento legal vigente no País, esta oferta corre o risco de retrocesso em termos da garantia de educação pública de qualidade para todos. 
Para explicarmos nosso ponto de vista, torna-se necessário revisar estudos com base na literatura internacional, que oferecem elementos teóricos para analisarmos a realidade local com base no contexto global (BALL; OLMEDO, 2013; ROBERTSON, 2012; ROBERTSON; VERGER, 2012; DALE, 2004, 2010) e em estudos nacionais (PERONI, 2015; PERONI, 2016; BORGHI; ADRIÃO; GARCIA, 2011), sistematizando resultados de pesquisas que aprofundam características e resultados de políticas públicas educacionais decorrentes de parcerias entre o setor público e o privado evidenciando que, apesar dessas parcerias, em geral, efetivarem uma ampliação do acesso para algum nível, etapa ou modalidade educacional, nem sempre esse direito a uma vaga traz consigo a garantia da qualidade, condição essencial para a efetivação do direito e democratização da educação (CURY, 2007).

$\mathrm{Na}$ atualidade, tem recebido destaque um modelo de atendimento às crianças de até seis anos de idade que pode colocar em risco o direito garantido no plano legal. Trata-se da expansão da oferta a partir da ampliação do número de convênios entre municípios e instituições privadas de caráter beneficente, filantrópico ou comunitário, política de atendimento que minimiza a responsabilidade do Estado e para a qual costuma prevalecer o menor custo, fragilizando, em certos casos, princípios constitucionais basilares do direito à educação, como a qualidade, a gratuidade e a gestão democrática (SUSIN, 2009; FLORES; SUSIN, 2013; SUSIN; MONTANO, 2015).

As tradicionais iniciativas da sociedade civil, surgidas como ação de caráter filantrópico ou beneficente, nos últimos anos, tem sido matizadas por novos discursos, reforçadas por argumentos do campo econômico e/ou das neurociências ou, ainda defendendo a educação e o empoderamento das famílias, trazendo à cena, novamente, a proposição de modelos não-formais de atendimento, que se somam a parcerias público-privadas. Tais proposições podem ser implementadas como ações intersetoriais derivadas de convênios entre diversas instituições e o poder público, incluindo, ou não, vinculação com a área da educação. Seja o conveniamento para atendimento em uma instituição ou para atendimento domiciliar, uma característica desses modelos é o baixo investimento por parte dos governantes, com precariedade em vários aspectos. A literatura aponta que organismos multilaterais defendem programas desse tipo para o caso de países "em processo de desenvolvimento", caso do Brasil, nos quais os investimentos no campo da educação deveriam priorizar a universalização do ensino fundamental (ROSEMBERG, 2002, 2003; CAMPOS; CAMPOS, 2009; SUSIN; MONTANO, 2015). 
Com base no estudo desse cenário, procuramos demonstrar no presente texto que, a despeito de um reconhecimento consolidado no plano normativo vigente, decorrente de várias décadas de atuação de movimentos de diversos setores da sociedade, a garantia do direito à educação infantil ainda está a exigir a materialização do acesso à primeira etapa da educação básica como política de Estado. Visando desenvolver as ideias aqui anunciadas, o artigo encontra-se organizado em duas seções que tematizam: o contexto recente de redefinição das fronteiras entre o público e o privado no cenário internacional e no Brasil, com ênfase no que se refere à oferta educacional; e as repercussões da influência desse contexto global nas políticas de oferta de atendimento para as crianças de até seis anos.

\section{REDEFINIÇÕES DAS FRONTEIRAS ENTRE O PÚBLICO E O PRIVADO}

Em 2004, Dale publicou pela primeira vez no Brasil um artigo sobre a teoria da Agenda Globalmente Estruturada para a Educação (AGEE), apresentando-a como uma possível ferramenta analítica para operarmos no campo das políticas educacionais, defendendo a análise ampliada dos contextos de globalização para a compreensão de uma política educacional local. Para Souza (2016, p. 463), tornase importante contextualizar a globalização se pretendemos explorar a potência da AGEE, sendo esta um cenário de organização político-econômica que envolve “[...] virtualmente todas as nações do planeta em um processo calcado no modo capitalista de produção, que é, inicialmente, econômico, mas que se estende à política e à cultura."

Para Dale (2004, p. 423), a abordagem pela AGEE implica compreender que existem “" [...] forças econômicas operando supra e transnacionalmente para romper, ou ultrapassar, as fronteiras nacionais, ao mesmo tempo em que reconstroem as relações entre as nações." Apoiado em estudos sobre economia política e trazendo essa abordagem para o campo das políticas educacionais, o autor reconhece que há espaços locais que podem redefinir uma agenda maior; contudo, haveria um peso especial ao termo "global", que no entendimento do autor indica com mais potência a operação das forças econômicas. Referindo-se aos impactos da globalização, o autor também questiona o entendimento de que a educação de massas se constitui em um "método científico de produzir progresso social", concebendo que a educação, 
[...] enquanto variável dependente neste processo, centra-se em três questões fundamentais: a quem é ensinado o quê, como, por quem e em que circunstâncias?; como, por quem e através de que estruturas, instituições e processos são definidas estas coisas, como é que são governadas, organizadas e geridas?; quais são as consequências sociais e individuais destas estruturas e processos? (DALE, 2004, p. 439).

Anunciando à época, uma mudança de paradigma na compreensão dessas relações, Dale (2004) afirmou os efeitos de uma economia globalizada sobre os sistemas educacionais e as políticas educativas de diferentes países, a partir da criação de modelos e protocolos a serem seguidos. Questionando a concepção de Myers em relação a um papel técnico-científico da política mundial baseada em Organizações Internacionais Não Governamentais (OING), Dale (2004) aponta fortes interesses das grandes potências na definição de políticas para outros países, chanceladas pelos próprios estados-membros.

Acreditando na produtividade do conceito de AGEE de Dale para pensarmos a influência dos organismos multilateriais sobre as políticas de educação infantil no Brasil, trazemos Robertson (2012) ao debate, quando esta trata da relação entre os setores público e privado, denominando esse processo de parcerias público-privadas (PPP), o qual se configura como,

[...] um guarda-chuva semântico que pode cobrir fenômenos bastante heterogêneos, que vão desde a prestação de serviços privados, acordos de serviços com base em contrato e tipos menos formais de colaboração e parceria entre o setor privado, organizações filantrópicas privadas e governos, com base na confiança e no compromisso conjunto para o bem comum. (ROBERTSON, 2012, p. 5).

Robertson e Verger (2012) dialogam com Dale (2004) no sentido de que uma definição política envolve, sempre, projetos societários, e que uma PPP não pode ser entendida como mero instrumento técnico, pois envolve, antes de tudo, relações sociais e econômicas. Robertson e Verger (2012) apresentam um histórico da relação públicoprivada, iniciando na década de 1970, com a crise do projeto de desenvolvimento capitalista do pós-guerra, em que ocorria um casamento entre liberalismo econômico e socialdemocracia. Nos anos 1980, ocorreu a introdução da economia de livre mercado como o modo dominante de organização da vida política e social. E, a partir do Consenso de Washington, as instituições do Estado foram reestruturadas com três objetivos principais: fazer com que o Estado servisse aos 
interesses dos negócios; remodelar suas operações internas sob a linha dos negócios e reduzir a exposição do governo à pressão política do eleitorado, o que passou a ser chamado de Nova Gestão Pública (NGP) (ROBERTSON; VERGER, 2012).

Os autores ressaltam, ainda, que nos anos 1990, o Banco Mundial (BM), o Fundo Monetário Internacional (FMI), a Organização para a Cooperação e o Desenvolvimento Econômico (OCDE) e a United States Agency for International Development (USAID) desempenharam papéis cada vez mais instrumentais no avanço das ideias do livre mercado como base para o desenvolvimento. Nos países ricos, no campo educacional, a OCDE desenvolveu semelhante agenda neoliberal de descentralização e autonomia institucional em oposição a formas burocráticas de organização e introdução da escolha dos pais. No entanto, nos países pobres, sob recomendação do BM, FMI e USAID, a agenda proposta foi a descentralização, a privatização e a cobrança de taxas, o que culminou em uma crescente polarização social e aumento nos níveis de desigualdade (ROBERTSON; VERGER, 2012).

Nesse contexto, os autores destacam que as "parcerias" surgiram no início de 1990, como um promissor mecanismo para minimizar os danos causados por formas anteriores de privatização, ainda que sem abandoná-las. As parcerias permitiram múltiplos enquadramentos, interesses e objetivos. No âmbito europeu, as parcerias foram um corretivo para a presença demasiada do Estado (keynesianismo), por um lado, e a ausência dele, em processos de privatização, por outro. Ao final dos anos 1990, o sistema das Nações Unidas focou nas parcerias, argumentando que, se os países buscavam alcançar as metas de desenvolvimento do milênio, seriam obrigados a avançar na direção de um novo paradigma de desenvolvimento. As parcerias também foram destacadas nos 10 princípios do Pacto Global das Nações Unidas (1999), cuja ênfase é o mercado e o empreendedorismo. (ROBERTSON; VERGER, 2012). A conclusão dos autores é a de que existe uma indústria especializada que surgiu em torno das parcerias público-privadas na educação (PPPE), que é composta por diferentes sujeitos com orientação pró-mercado:

Essa indústria, que de forma crescente exporta globalmente sua expertise, inclui um número crescente de atores privados, de fundações, de empresas especializadas em PPPEs, de firmas globais e locais de consultorias, de bancos, think tanks, de sites especializados, equipes de acompanhamento da mídia e escritórios de advocacia, que cada vez mais atuam como fontes de autoridade com orientação pró-mercado. (ROBERTSON; VERGER, 2012, p. 12). 
Nesse contexto, preocupa ainda, o fato de a educação passar de uma perspectiva de direito e de responsabilidade e regulação por parte do poder público para um serviço a ser comercializado e regulado internacionalmente, pois no Brasil, a democracia é conquista recente e em construção, pois o Estado foi, historicamente, vinculado aos interesses privados (PIRES, 2015). Após o último período de ditadura, a partir de meados dos anos 1980, entrou na pauta da sociedade, mesmo que de forma tímida, o processo de democratização, participação, coletivização das decisões, assim como direitos sociais materializados em políticas. Ao mesmo tempo, os processos de neoliberalismo, reestruturação produtiva e financeirização redefiniam o papel do Estado para com as políticas sociais, com um diagnóstico de crise fiscal e redução de custos. Vivemos, então, o que chamamos de um processo de "naturalização do possível", isto é, a população, que mal tinha iniciado a luta por direitos sociais para todos e com qualidade, acaba aceitando políticas focalizadas, muitas vezes, ofertadas por instituições filantrópicas e com recursos precários (FLORES, PERONI, 2016).

Pesquisas demonstram que, no Brasil, o processo de privatização do público ocorre tanto pela "direção da proposta" quanto pela "execução da proposta" ou de ambas (PERONI, 2016). No primeiro caso, um exemplo é o Movimento Todos pela Educação, em que os empresários influenciam as ações do governo central, tanto na agenda educacional quanto na venda de produtos no Guia de Tecnologias do Ministério da Educação (BERNARDI; UCZAK; ROSSI, 2015). Outro exemplo nesse sentido é a assessoria do grupo internacional McKinsey \& Company ao governo federal, conforme analisaram Bittencourt e Oliveira (2013).

No processo de privatização para a execução da proposta, são exemplos a expansão da oferta de educação infantil via terceiro setor a partir de convênios do poder público com creches comunitárias ou filantrópicas (SUSIN, 2009; BORGHI; ADRIÃO; GARCIA, 2011; FLORES; SUSIN, 2013) e os Programas de Educação de Jovens e Adultos, como o Brasil Alfabetizado (COMERLATO; MOARES, 2013). Ainda nesses moldes de privatização, na Educação profissional temos o Programa Nacional de Acesso ao Ensino Técnico e Emprego (PRONATEC), analisado por Rodrigues e Santos (2013).

Em seu conjunto, os estudos citados destacam que essas políticas e/ou programas incidem, principalmente, sobre a oferta de atendimento para pessoas que compõem os grupos sociais mais vulneráveis e, com algumas exceções, ocorre de 
forma precarizada, realizada por profissionais com pouca formação ou experiência, que recebem bolsas ou salários simbólicos, atuam em locais pouco apropriados e em contextos que inviabilizam, ainda, espaços democráticos de participação. Entendemos que, em uma sociedade democrática, as instituições públicas devem atuar em um processo formativo de coletivização das decisões, com espaços de participação que devem ser cada vez mais alargados. O "público", em oposição ao "privado", nesse sentido, está sendo construído em um processo de correlação de forças e está intimamente vinculado com as possibilidades de efetivação de um modelo/regime democrático (PERONI, 2016).

Apontamos, ainda, que os processos de privatização da educação pública podem ocorrer, concomitantemente, em ações de execução e de direção da política. Nesses casos, as instituições privadas definem o conteúdo da educação e, também, executam sua proposta a partir de ações como formação de profissionais, monitoramento e avaliação dos processos, premiação e sanções aplicadas às instituições, permitindo um controle rigoroso de que sua proposta está sendo executada (PERONI, 2016). Na seção seguinte, resgatamos brevemente a trajetória de consolidação da educação infantil, enfatizando a constituição de um ordenamento legal e de uma arcabouço teórico potentes no sentido de afirmação desse direito social.

\section{EDUCAÇÃO INFANTIL: A AFIRMAÇÃO DOS DIREITOS NO PLANO DOCUMENTAL}

A trajetória da educação infantil como etapa educacional é bastante recente, se comparada aos demais níveis da educação básica. Ainda que tenha havido diversos movimentos encaminhando para tal reconhecimento em décadas anteriores, os principais documentos e políticas que afirmam a constituição desse direito datam a partir de 1988, quando se estabelece um conjunto normativo regulador que, em muito, contribuiu para orientar a recente expansão dessa oferta no campo educacional, situando-a no conjunto do ordenamento legal educacional.

Em que pesem a força do conjunto normativo vigente, dos documentos de caráter orientador para essa oferta e dos avanços teóricos da área, nosso objetivo neste texto é evidenciar que, no que se refere ao plano da implementação de políticas de atendimento, essa etapa vive, atualmente, mais uma investida no sentido daquilo que Rosemberg (2002, 2003), chamou de metáfora do Mito de Sísifo, evidenciando projetos 
em disputa entre "[...] as forças progressistas que empurram a política de educação infantil para o topo - isto é, um atendimento democrático de qualidade -, e as forças contrárias que a fazem despencar morro abaixo [...]” (ROSEMBERG, 2003, p. 177).

Rosemberg (2003) debruçou-se sobre documentos de organismos internacionais e propostas nacionais apontando a influência da Organização das Nações Unidas para a Educação, Ciência e Cultura (Unesco) e do Fundo das Nações Unidas para a Infância (Unicef) desde a década de 1970 e, do Banco Mundial, especialmente, a partir dos anos 1990, e identificou a existência de três momentos da história das políticas de educação infantil brasileira contemporânea: “[...] a fase de expansão durante o governo militar; as inovações trazidas pela Constituição de 1988; e o impacto das reformas educacionais contemporâneas sob a égide do Consenso de Washington.” (ROSEMBERG, 2003, p. 177). Abordando os processos que levam à constituição de uma "comunidade epistêmica" com aval para embasar a definição de políticas, a autora qualifica um organismo internacional como uma estrutura que "[...] possui as informações consideradas pertinentes, o poder de financiamento e os meios para influenciar certas categorias de atores nacionais." (ROSEMBERG, 2003, p. 179). Segundo a autora, esse grupo "[...] dispõe de canais importantes para construir o senso comum e o repertório de argumentos para apoiar decisões políticas [...]”, a partir do financiamento de pesquisas de larga escala e de processos formativos de lideranças, ações estas que se configuram, normalmente, como incompatíveis com as condições de produção e análise de dados dos próprios países onde tais organismos se dispõem a atuar. Porém, como já afirmou Dale (2002), Rosemberg (2003) afirma que, na medida de suas condições, cada estado-membro poderia propor adequações e ajustes às proposições desses organismos a sua realidade local, atuando na margem de negociação existente.

Resgatando os dois modelos básicos de atendimento às crianças pequenas vigentes até os anos sessenta, tanto em países desenvolvidos quanto nos demais, Rosemberg (2003) põe em destaque as creches, modelo voltado prioritariamente à população pobre, e os jardins de infância, dirigidos às crianças de outros grupos sociais. Esse modelo dual teria se mantido, grosso modo, até que as crianças pequenas passaram a ser objeto de interesse das políticas econômicas e sociais de organismos multilaterais, como Unesco e Unicef. Para essa autora, em países desenvolvidos, graças à posição de diferentes atores sociais, prevaleceram as instituições do segundo modelo. 
Nos documentos dos organismos multilaterais estudados por Rosemberg (2003), destaca-se o entendimento de que, em países subdesenvolvidos, que ainda precisavam universalizar a oferta de ensino fundamental, o atendimento às crianças de até seis anos de idade constava como recomendado dentro de parâmetros nãoformais, de menor custo, utilizando recursos humanos das próprias comunidades, sendo a expansão da oferta de atendimento para as crianças pequenas colocada como: “[...] uma via para combater a pobreza (especialmente desnutrição) no mundo subdesenvolvido e melhorar o desempenho do ensino fundamental." (ROSEMBERG, 2003, p. 180). Essas propostas chegam ao Brasil e aqui proliferam durante o regime militar em um cenário de pouca condição de questionamento de tais pressupostos pela insuficiência de outras experiências e de acúmulo da área e, ainda, de profissionais habilitados, deixando, na avaliação de Rosemberg (2003), uma herança nefasta.

Mais adiante, com o fim da ditadura militar, na esteira dos movimentos democráticos da década de 1980, também as crianças pequenas passam a ser defendidas como sujeitos de direitos, incluindo-se, entre estes, a educação. Como principais dispositivos legais nesse sentido, destacamos a Constituição Federal de $1988(\mathrm{CF} / 88)$ que assegura esse direito às crianças e as suas famílias (art. $7^{\circ} \mathrm{e}$ art. $8^{\circ}$ ) (BRASIL, 1988), apoiando, assim, o trabalho das mulheres fora do lar. O Estatuto da Criança e do Adolescente (Lei n. 8.069/90 - ECA) colocou esses grupos geracionais no lugar de centralidade no sistema de garantia de direitos. Nos anos seguintes, a Coordenação de Educação Infantil do Ministério da Educação (MEC) propôs uma Política de Educação Infantil que defendia a superação dos modelos de baixo custo, preconizando a exigência de formação em nível médio ou superior para as profissionais em atuação na área (ROSEMBERG, 2003).

A partir de 1994, no Governo Fernando Henrique Cardoso, foram adotadas algumas medidas no plano econômico sob a orientação do FMI e, em paralelo, no plano educacional, foram assumidas proposições do BM, retomando-se no País a opção pela priorização de investimentos no ensino fundamental e a adoção de modelos de baixo custo para o atendimento às crianças menores de sete anos de idade, acentuando-se, ainda mais, o círculo da pobreza entre famílias com baixa renda e baixo índice de escolaridade. Santos (2015) aponta as consequências da criação do Fundo de Manutenção e Desenvolvimento do Ensino Fundamental e de Valorização do Magistério (Fundef) para a trajetória de consolidação da educação infantil, dado que o modelo de remuneração exclusiva das matrículas do ensino fundamental, na 
maior parte do País, resultou em exclusão sumária dos investimentos na expansão da educação para a faixa etária anterior a este.

Em meados dos anos 1990, após oito anos de discussão no Congresso Nacional, a Lei de Diretrizes e Bases da Educação Nacional (LDBEN n. 9.394/96) reconheceu a educação infantil como a primeira etapa da educação básica; e, a seguir, a Emenda Constitucional n 53/07 criou o Fundo de Manutenção e Desenvolvimento da Educação da Educação Básica e de Valorização dos Profissionais da Educação (Fundeb), regulamentado pela Lei n. 11.494/07, dispondo sobre a remuneração das matrículas para toda a educação básica. Apesar da inclusão da educação infantil nesse Fundo, os recursos repassados aos municípios, responsáveis prioritários pela oferta de educação infantil de acordo com a Constituição Federal de 1988, (art. 211, $\S 2^{\circ}$ ) (BRASIL, 1988) não contemplam a integralidade dos insumos necessários, especialmente no caso do atendimento para crianças de até três anos de idade, na medida em que as condições adequadas de infraestrutura das instituições e o número de profissionais, dentre outros aspectos, exigem maiores investimentos devido a especificidades da faixa etária.

Como documento específico de caráter normativo em vigência, temos a Resolução CNE/CEB n 5/2009 que, apoiada no Parecer CNE/CEB n. 20/2009, fixa as Diretrizes Curriculares Nacionais para a Educação Infantil (DCNEI). Ainda, em 2009, a EC n 59 ampliou a faixa etária de educação escolar obrigatória no Brasil, abarcando aquela entre os quatro e os 17 anos, fato que, ao tornar obrigatória a matrícula das crianças da pré-escola em um contexto de recursos insuficientes, coloca em risco o atendimento educacional público de qualidade para aquelas de até três anos de idade e a própria unidade da educação infantil (FLORES et al., 2010; ROSEMBERG, 2015; BONNEAU, 2016). A Lei n. 13.005/2014 criou o Plano Nacional de Educação 2014-2024 (PNE), onde se encontra determinada na Meta 1 a matrícula universal das crianças de quatro e cinco anos de idade até 2016.

Do ponto de vista dos avanços científicos, a educação infantil brasileira percorreu importante caminho nas últimas décadas do século passado e primeiros anos deste, realizando avanços do ponto de vista da concepção de criança, infância e educação infantil, conforme expresso nas atuais DCNEI. Reconhecida a diversidade presente nas formas de vivência da infância em um País com tal extensão territorial, marcado por imensas desigualdades sociais, a área construiu significativa produção, com apoio de diferentes campos do conhecimento, postulando a potência das crianças, 
como sujeitos de conhecimento e construtores de uma cultura de pares, desde os bebês (BARBOSA; RICHTER, 2010), o que demanda a construção de uma proposta curricular própria e que considere os tempos da infância (HOYUELOS, 2015) e a singularidade da vivência das experiências educativas de cada grupo nas instituições de educação coletiva, entendendo o desenvolvimento como processo conjunto e recíproco (OLIVEIRA, 2014).

Contribuindo para esse reconhecimento do direito à educação infantil nos dispositivos legais, há mais de duas décadas, a Coordenação da Educação Infantil da Secretaria de Educação Básica do Ministério da Educação (COEDI/SEB/MEC), visando induzir à implementação de políticas educacionais no âmbito dos estados e municípios, em consonância com os parâmetros de qualidade, promoveu a realização de grupos de trabalho e apoiou pesquisas que levaram à produção de publicações distribuídas às redes e aos sistemas de ensino. ${ }^{3} \mathrm{Na}$ seção seguinte, argumentamos no sentido de que, a despeito da trajetória aqui trazida, essa etapa educacional corre riscos à sua implementação dentro de parâmetros de qualidade no contexto atual da matrícula escolar obrigatória na pré-escola.

\section{EDUCAÇÃO INFANTIL COM QUALIDADE: DIREITO EM RISCO}

Diferentemente do padrão filantrópico vigente em meados do século passado, na atualidade, coexistem, basicamente, dois modelos que, em nosso entendimento, tendem a um retrocesso em termos de concepção de atendimento, ambos fazendo uso de parcerias público-privadas, e apoiados em discursos de enxugamento do Estado e redução de custos para o setor público: (1) as políticas de conveniamento entre prefeituras e instituições privadas classificadas como sem fins lucrativos, desenvolvendo atendimentos vinculados à educação e financiados com recursos do Fundeb; e (2) programas alternativos, também chamados de modelos "não formais", articulando ações que podem envolver diferentes secretarias (saúde, assistência social, educação), com atuação de leigos (voluntários ou estudantes estagiários) e que focam na educação das famílias. Com a obrigatoriedade de matrícula escolar na

\footnotetext{
3 Entre os documentos, todos disponíveis no Portal do MEC, destacamos: Critérios para um atendimento em creche que respeite os direitos fundamentais das crianças (BRASIL, 1995); Indicadores da Qualidade na Educação Infantil (BRASIL, 2009c); a Avaliação em Educação Infantil a partir da avaliação de Contexto (BRASIL, 2015).
} 
pré-escola, alguns municípios têm expandido o atendimento dessa faixa etária em escolas que antes atendiam exclusivamente ao ensino fundamental, em turno parcial, e priorizaram as vagas da rede própria para as crianças de quatro e cinco anos de idade, ampliando convênios com instituições privadas como forma de atendimento para as crianças de até três anos (FLORES; BRUSIUS; FRAGA, 2016).

É possível afirmar que as políticas de conveniamento, apesar de serem realizadas com recursos públicos, ao mesmo tempo, se efetivam de uma forma em que a responsabilização do poder público estadual ou municipal em relação ao conteúdo e qualidade da ação apresenta-se frágil, posto que a gestão da mesma coloca-se como de responsabilidade das instituições que desenvolvem as ações, sendo, portanto, em última instância, privatizada. No caso dos convênios, o repasse de recursos públicos para organizações sociais para fins de execução e a dependência das prefeituras em relação a esse atendimento gera uma situação na qual tanto a fiscalização quanto o controle social restam prejudicados (FLORES; SUSIN, 2013). Um exemplo nesse sentido é o caso dos conveniamentos em Porto Alegre, capital do Rio Grande do Sul, que já foram alvo de auditoria por parte do Tribunal de Contas (TCE/RS).

Essa capital, desde 1993, com o fechamento da Legião Brasileira de Assistência (LBA), começou a conveniar com creches comunitárias, beneficentes e filantrópicas, oferecendo repasse de recursos, assessoria pedagógica e assistência para a realização de prestação de contas. Com o passar de sucessivas administrações, essa Prefeitura de Porto Alegre ampliou a política de convênios como a principal opção para a expansão da rede de atendimento no Município (SUSIN, 2009), apresentando, em 2016, “[...] uma conjuntura, em geral, desfavorável aos alunos da rede conveniada, com prejuízos em termos de qualidade dos serviços prestados e infringindo o princípio da gratuidade." (ROCHA; PESSANHA, 2016, p. 34). Mais recentemente, unidades construídas com recursos do Programa Nacional de Reestruturação e Aquisição de Equipamentos para a Rede Escolar Pública de Educação Infantil - Proinfância, também, foram objeto de conveniamento, ficando sua gestão sob a responsabilidade de instituições privadas.

Segundo resultados da auditoria realizada pelo TCE/RS, em Porto Alegre, acerca das diferenças entre o atendimento na rede escolar própria e nas instituições conveniadas, destacaram-se a estrutura física e condições das edificações, as condições de nutrição, quantidade e qualidade de materiais pedagógicos, sendo o investimento médio na rede conveniada $35 \%$ menor do que aquele na rede própria. 
Analisando documentos do Banco Mundial que visam influenciar as políticas educacionais brasileiras na direção das parcerias público-privadas, Susin e Montano (2015, p. 77, grifo do autor) destacam a defesa de aspectos como a "[...] capacidade de 'alavancagem de agentes não públicos' na expansão da educação infantil”" e a afirmação de que “[...] as instituições privadas prestam 'cuidados' de qualidade superior e educação a custo igual ou inferior ao custo público [...]" Para as autoras, a sociedade civil, quando parceira do Estado nos vários modelos de conveniamento, reduz o investimento necessário adequando-se aos recursos públicos recebidos, enxugando custos com a "[...] contratação de profissionais não habilitados, ou, quando habilitados, a sua contratação (se dá) como técnicos de educação cujos salários são inferiores aos dos professores.” (SUSIN; MONTANO, 2015, p. 77).

O estudo longitudinal de Flores, Brusius e Fraga (2016) evidenciou que vários municípios da Região Metropolitana de Porto Alegre, na última década, vêm realizando convênios como uma opção política para a gestão de novas unidades, ampliando o atendimento, conforme determina o atual PNE, mas enfraquecendo a atuação do Estado como responsável pela educação na faixa etária obrigatória. Como assinalou Rosemberg (2002), o crescimento do atendimento a partir de opção de menor custo e qualidade é perversa, uma vez que penaliza, especialmente, as crianças de grupos sociais mais vulneráveis, prejudicando mais àquelas de até três anos de idade.

O segundo modelo que identificamos em termos de políticas de atendimento refere-se a investimentos na primeira infância por coletivos de empresários, articulados como investidores sociais privados, organizados em institutos ou fundações, e que atuam diretamente em consultorias e formação de profissionais, apoio à oferta de atendimento, gestão dos serviços, produção de materiais, ações que repercutem, direta ou indiretamente, na definição do conteúdo de propostas curriculares, entendidas como de “direção da proposta". (PERONI, 2016). Coexistem, ainda, à oferta educacional, com apoio de especialistas de diversas áreas, programas de atendimento domiciliar realizados em contextos de vulnerabilidade que visam à educação das famílias cujas crianças não têm acesso à vaga em instituições de educação infantil (CAMPOS; CAMPOS, 2009).

O apoio dos organismos multilaterais aos modelos alternativos para países ditos em desenvolvimento ganha importante impulso na atualidade, a partir do uso de dois argumentos que se somam: discursos acerca de uma crise na economia, global e local, que exigiria cortes de gastos em áreas sociais com enxugamento da 
máquina pública e a difusão de conhecimentos de áreas biomédicas acerca das janelas de oportunidades para a aprendizagem nos primeiros mil dias de vida das crianças, cenário propício a propostas de atendimentos não formais para esses grupos, como afirmam Flores et al. (2010), Campos et al. (2010) e Rosemberg (2015).

No Brasil, foi lançado recentemente pelo Governo Federal o Programa Criança Feliz ${ }^{4}$ voltado a famílias de baixa renda vinculadas ao Programa Bolsa Família, com algumas das características recomendadas por organismos multilaterais para programas voltados a populações de baixa renda, tais como visitas domiciliares semanais de acompanhamento utilizando profissionais, estrutura e recursos de outras áreas, estando previsto o atendimento a mais de 4 milhões de crianças em todo o País até 2018 (PORTAL BRASIL, 2016).

Programas dessa natureza proliferaram no País nos últimos anos, ${ }^{5}$ alinhando objetivos econômicos e de prevenção da pobreza, materializando desdobramentos dos estudos como o do economista estadunidense James Joseph Heckman, Prêmio Nobel de Economia no ano 2000 pelo desenvolvimento de um método de análise de dados estatísticos que deu sustentação a estudos na área das ciências humanas, incluindo-se a avaliação de programas sociais. Participando de vários eventos no País nos últimos anos, Heckman disseminou largamente suas ideias entre grupos de investidores sociais privados e políticos. ${ }^{6}$

Contribuem para a compreensão desse contexto os estudos de Ball e Olmedo (2013), descrevendo que, desde a década de 1990, diferentes modelos de privatização ressurgem em vários países, dando condições para o crescimento de uma

\footnotetext{
4 Coordena esse Programa o Dr. Osmar Terra, Ministro do Desenvolvimento Social e Agrário desde agosto de 2016, sendo o idealizador do Programa Primeira Infância Melhor (PIM), de atendimento domiciliar, desenvolvido no Rio Grande do Sul, desde que era Secretário de Saúde nesse Estado e ex-presidente da Frente Parlamentar da Primeira Infância da Câmara dos Deputados.

5 Podemos citar aqui os programas Mãe Coruja Pernambucana, o Primeira Infância Melhor, do Rio Grande do Sul, o Família que Acolhe, de Boa Vista (AC) e o Programa Família Paulista, todos citados como referências para o Programa Criança Feliz.

6 Heckman foi conferencista em 16 de abril de 2013, no Seminário Internacional Construção do Marco Legal para as Políticas Públicas sobre Primeira Infância realizado na Câmara dos Deputados, por meio da Frente Parlamentar da Primeira Infância da Câmara dos Deputados; Comitê Diretivo da Rede Hemisférica de Parlamentares e ex-Parlamentares pela Primeira Infância; Comissão de Seguridade Social e Família da Câmara dos Deputados; Comissão de Educação e Cultura da Câmara dos Deputados; Projeto O Direito a um Bom Começo na Amazônia, com o apoio da Fundação Bernard van Leer; Secretaria de Assuntos Estratégicos da Presidência da República; Fundação Maria Cecília Souto Vidigal; Organização dos Estados Americanos (OEA); Secretaria de Direitos Humanos da Presidência da República; Ministério de Desenvolvimento Social e Combate à Fome; Ministério da Educação; e Ministério da Saúde (CÂMARA DOS DEPUTADOS, 2013).
} 
nova filantropia que passa a prestar serviços de responsabilidade do Estado. Para esses autores, caracteriza esse novo modelo de filantropia a atuação de grupos empresariais em parceria com organismos internacionais, a partir da construção de oportunidades de atuação em causas sociais, mas de maneira vinculada a uma expectativa de lucro, podendo essa atuação ocorrer em diversas áreas, incluindo a oferta educacional.

Embasados nesses pressupostos, nos últimos anos, é possível identificar o fortalecimento de modelos nos quais a privatização pode ser efetuada a partir do conteúdo da proposta quando atores da iniciativa privada são colocados em um lugar de reconhecido saber em relação às melhores formas de atendimento e educação para as crianças pequenas, materializando-se, com esses novos atores sociais, aquilo que Rosemberg (2003) nomeou como a constituição de uma "comunidade epistêmica", com acesso e voz nas esferas de definição de políticas. Dale (2010) alertou para as novas formas de atuação do Estado no contexto da "governança educacional", em que diferentes agentes podem realizar partes do processo, tais como as famílias, mercado, comunidade.

Com essas análises, buscamos evidenciar que, de certa forma, continuam convivendo no País movimentos contraditórios no que se refere à concepção de atendimento para as crianças de até seis anos de idade: por um lado, significativas lutas em prol do reconhecimento de seu status educacional se materializam na oferta de educação de qualidade para certos grupos, enquanto, pari passu, resultado de um processo de correlação de forças, são desenvolvidas propostas e ações sustentadas em concepções de viés compensatório, que negam a consolidação da educação infantil como direito educacional para todas as crianças, atingindo diretamente grupos mais vulneráveis da população.

\section{CONSIDERAÇÕES FINAIS}

O objetivo com este texto foi evidenciar que, apesar de alguns avanços ocorridos ao longo das últimas décadas, coexistem certas tensões presentes no campo das políticas educacionais no sentido da efetivação do direito à educação infantil no Brasil. Para tanto, resgatamos avanços materializados em documentos legais reguladores, bem como outras políticas que contribuíram para a construção da concepção de que essa é a primeira etapa da educação básica, cuja oferta deve ser integrada aos sistemas de ensino atendendo às normativas vigentes. 
Porém, em que pese os avanços destacados, também enfatizamos que, em paralelo e de maneira bastante forte, persiste nas diversas arenas decisórias outro entendimento sobre como deve se efetivar o atendimento às crianças de até seis anos de idade, o que fragiliza os avanços registrados, marcando a trajetória da etapa por sucessivos ataques aos direitos estabelecidos.

Em especial, procuramos demonstrar que um movimento privatista, presente de maneira global na área da educação sob a forma de PPPE, tem se fortalecido nas últimas décadas em nosso País, nas diferentes etapas e modalidades da educação, com um discurso marcado pela desconstituição da educação pública e a defesa de parcerias público-privadas e de conveniamentos desde diferentes arranjos, abrindo espaço para uma nova filantropia, do "tipo 3.0", como apontam Ball e Olmedo (2013). Nesse contexto e, para o caso deste artigo, evidenciamos movimentos de influência de organismos multilaterais no sentido de direcionamento de países identificados como “em desenvolvimento" para a proposição de políticas subordinadas a uma agenda global, como nomeou Dale (2004), agenda que defende baixo investimento por parte do poder público e maior responsabilização da sociedade civil.

Entendemos que a implementação de programas e ações desse tipo no Brasil reforça as desigualdades sociais históricas (ROSEMBERG, 2002, 2003), promovendo propostas de atendimento que contradizem os princípios da atual $\mathrm{CF} / 88$, que propugna o dever do Estado para com a educação pública, gratuita e de qualidade para todas as crianças de até seis anos de idade. Nesse sentido, argumentamos que a consolidação da concepção de educação infantil presente nos dispositivos legais vigentes encontra-se ameaçada, pois a redução de investimentos em educação pode levar a flexibilizações e retrocessos em termos de parâmetros de qualidade, bem como do conteúdo curricular, fragilizando conquistas recentes no âmbito da democratização da educação, mesmo que alguma ampliação da oferta de vagas se efetive.

\section{REFERÊNCIAS}

BALL, S.; OLMEDO, A. A 'nova' filantropia, o capitalismo social e as redes de políticas globais em educação. In: PERONI, V. (Org.). Redefinições das fronteiras entre o público e o privado: implicações para a democratização da educação. Brasília: Liber Livro, 2013. p. 33-47.

BARBOSA, M. C. S.; RICHTER, S. R. Os bebês interrogam o currículo: as múltiplas linguagens na creche. Educação, v. 35, n. 1, p. 85-96, jan./abr. 2010. 
BERNARDI, L. M.; UCZAK, L. H.; ROSSI, A. J. As relações do estado com empresários nas políticas educacionais: PDE/PAR e guia de tecnologias educacionais. In: PERONI, V. (Org.). Diálogos sobre as redefinições no papel do Estado e nas fronteiras entre o público e o privado na educação. São Leopoldo: Oikos, 2015. p. 52-71.

BITTENCOURT, J. M. V.; OLIVEIRA M. de F. A influência das consultorias internacionais nas decisões das políticas educacionais no Brasil. In: PERONI, V. (Org.). Redefinições das Fronteiras entre o Público e o Privado: implicações para a democratização da educação. Brasília, DF: Liber Livro, 2013. p. 175-197.

BONNEAU, C. S. Políticas de educação infantil no Município de Canoas: um estudo de caso (2009-2015). Canoas: Unilasalle, 2016. 126 p. Dissertação (Mestrado em Educação)-Centro Universitário La Salle, Canoas, 2016.

BORGHI, R.; ADRIÃO, T.; GARCIA, T. As parcerias público-privadas para a oferta de vagas na educação infantil: um estudo em municípios paulistas. Revista Brasileira de Estudos Pedagógicos, Brasília, v. 92, n. 231, p. 285-301, maio/ago. 2011.

BRASIL. Congresso Nacional. Constituição da República Federativa do Brasil. Texto constitucional promulgado em 05 de outubro de 1988. São Paulo: Revista dos Tribunais, 2014.

BRASIL. Conselho Nacional de Educação. Parecer CNE/CEB n. 20, de 11 de novembro de 2009. Revisão das Diretrizes Curriculares para a Educação Infantil. Diário Oficial da União, Brasília, DF, 2009b.

BRASIL. Conselho Nacional de Educação. Resolução CNE/CEB n. 5, de 17 de dezembro de 2009. Fixa as Diretrizes Curriculares Nacionais para a Educação Infantil. Diário Oficial da União, Brasília, DF: 18 dez. 2009a.

BRASIL. Lei n 13.005, de 25 de junho de 2014. Aprova o Plano Nacional de Educação - PNE e dá outras providências. Diário Oficial da União, Brasília, DF, 26 jul. 2014. Disponível em: <http://www.planalto.gov.br/ccivil_03/_ato2011-2014/2014/ lei/113005.htm>. Acesso em: 27 abr. 2016.

BRASIL. Lei n. 8069/90, de 13 de julho de 1990. Dispõe sobre Estatuto da Criança e do Adolescente e dá outras providências. Diário Oficial da União, Brasília, DF, 14 jul. 1990.

BRASIL. Lei n. 9.394, de 20 de dezembro de 1996. Estabelece as Diretrizes e Bases da Educação Nacional. Diário Oficial da União, Brasília, DF, 21 dez. 1996. 
BRASIL. Ministério da Educação. A avaliação em educação infantil a partir da avaliação de contexto. MEC/SEB/COEDI. Curitiba: Imprensa/UFPR, 2015.

BRASIL. Ministério da Educação. Critérios para um atendimento em creche que respeite os direitos fundamentais das crianças. Brasília, DF: MEC/SEB, 1995.

BRASIL. Ministério da Educação. Indicadores da Qualidade na Educação Infantil. Brasília, DF: MEC/SEB, 2009c.

CÂMARA DOS DEPUTADOS. Discursos e notas taquigráficas. 2013. Disponível em: $<$ http://www.camara.leg.br/internet/sitaqweb/textoHTML.asp?etapa=11\&nuSe ssao $=0312 / 13 \&$ nuQuarto $=0 \&$ nuOrador $=0 \&$ nuInsercao $=0 \&$ dtHorarioQuarto $=09: 00$ $\&$ sgFaseSessao $=\&$ Data $=16 / 4 / 2013 \&$ txApelido $=$ SEGURIDADE $\% 20$ SOCIAL $\% 20$ E\%20FAM $\%$ C3\%8DLIA\&txFaseSessao=Semin $\%$ C3\%A1rio\&txTipoSessao $=\& d t H$ oraQuarto=09:00\&txEtapa $=>$. Acesso em: 12 dez. 2016.

CAMPOS, M. M. et al. (Org.). Insumos para o debate 2. Emenda Constitucional n. ${ }^{\circ}$ 59/2009 e a educação infantil: impactos e perspectivas. São Paulo: Campanha Nacional pelo Direito à Educação, 2010.

CAMPOS, R.; CAMPOS, R. F. A educação das famílias pobres como estratégia política para o atendimento das crianças de 0 a 3 anos: uma análise do Programa Família Brasileira Fortalecida. Pro-Posições, Campinas, v. 2, n. 1, p. 207-224, jan./ abr. 2009.

COMERLATO, D. M.; MORAES, J. C. AlfaSol e Programa Brasil Alfabetizado: a parceria público-privada nas políticas de educação de jovens e adultos. In: PERONI, V. (Org.). Redefinições das fronteiras entre o público e o privado: implicações para a democratização da educação. Brasília, DF: Liber Livro, 2013. p. 327-346.

CURY, C. R. J. A gestão democrática na escola e o direito à educação. RBPAE, v. 23, n. 3, p. 483-495, set./dez. 2007.

DALE, R. Globalização e educação: demonstrando a existência de uma "Cultura Educacional Mundial Comum” ou localizando uma "Agenda Globalmente Estruturada para a Educação?” Educação \& Sociedade, Campinas, v. 25, n. 87, p. 423-460, maio/ago. 2004.

DALE, R. A Sociologia da Educação e o Estado após a globalização. Educação \& Sociedade, Campinas, v. 31, n. 113, p. 1099-1120, out./dez. 2010.

FLORES, M. L. R.; BRUSIUS, A.; FRAGA, T. G. Obrigatoriedade de matrícula na pré-escola: estudo de caso em três municípios do Rio Grande do Sul. In: SEMINÁRIO DE GRUPOS DE PESQUISA SOBRE CRIANÇAS E INFÂNCIAS, 2016, Florianópolis. Anais... Florianópolis, 2016. 
FLORES, M. L. R. et al. Estratégias de incidência para a ampliação do acesso à educação infantil. Insumos para o Debate 2. Emenda Constitucional no 59/09 e a educação infantil: impactos e perspectivas. São Paulo: Campanha Nacional pelo Direito à educação, 2010.

FLORES, M. L. R.; PERONI, V. M. V. Sistema e Plano Nacional de Educação: articulações e tensões para a gestão democrática no contexto de 20 anos de LDBEN In: BATISTA, N. C.; FLORES, M. L. R. Formação de Gestores escolares para a educação básica: avanços e desafios frente aos 20 anos de normatização da gestão democrática LDBEN. 1. ed. Porto Alegre: Evangraf, 2016. v. 1, p. 79-105.

FLORES, M. L. R.; SUSIN, M. O. K. Expansão da educação infantil através da parceria público-privada: algumas questões para o debate quantidade versus qualidade no âmbito do direito à educação. In: PERONI, V. (Org.). Redefinições das fronteiras entre o público e o privado: implicações para a democratização da educação. Brasília, DF: Liber Livro, 2013. p. 220-243.

HOYUELOS, A. Os tempos da infância. In: FLORES, M. L. R.; ALBUQUERQUE, S. S. de. (Org.). Implementação do Proinfância no Rio Grande do Sul: perspectivas políticas e pedagógicas. Porto Alegre: EDIPUCRS, 2015. p. 39-56.

OLIVEIRA, Z. M. R. de. Currículo na educação infantil: dos conceitos teóricos à prática pedagógica. In: SANTOS, M.; RIBEIRO, M. I. S. (Org.). Educação Infantil: os desafios estão postos e o que estamos fazendo? Salvador: Sooffset, 2014. p. 187-193.

PERONI, V. Implicações da relação público-privada para a democratização da educação no Brasil. In: PERONI, V. (Org.). Diálogos sobre as redefinições no papel do Estado e nas fronteiras entre o público e o privado na educação. São Leopoldo: Oikos, 2015. p. 15-34.

PERONI, V. Implicações da relação público-privada para a democratização da educação no Brasil. 2016. Tese (promoção a Professor Titular da Carreira do Magistério Superior)-Faculdade de Educação, Universidade Federal do Rio Grande do Sul, Porto Alegre, 2016. Disponível em: <https://plone.ufrgs.br/gprppe/teses>. Acesso em: 23 mar. 2016.

PERONI, V. M. V.; FLORES, M. L. R. Sistema nacional, plano nacional e gestão democrática da educação no Brasil: articulações e tensões. Educação, v. 37, p. 180$189,2014$.

PIRES, D. de O. A construção histórica da relação público-privada na promoção do direito à educação no Brasil. 2015. Tese (Doutorado em Educação)-Universidade Federal do Rio Grande do Sul, Porto Alegre, 2015. 
PORTAL BRASIL. Programa Criança Feliz será baseado em experiências regionais. 2016. Disponível em: < http://www.brasil.gov.br/cidadania-e-justica/2016/09/ programa-crianca-feliz-sera-baseado-em-experiencias-regionais $>$. Acesso em: 19 dez. 2016.

ROBERTSON, S. A estranha morte da privatização neoliberal. Revista Brasileira de Educação, São Paulo, v. 17, n. 50, p. 283-304, maio/ago. 2012.

ROBERTSON, S.; VERGER, A. A origem das parcerias público-privada na governança global da educação. Educação \& Sociedade, Campinas, v. 33, n. 121, p. 1133-1156, out./dez. 2012.

RODRIGUES, R. de O.; SANTOS, M. I. O Programa Nacional de Acesso ao Ensino Técnico e Emprego - Pronatec: um olhar a partir das relações entre o público e o privado. In: PERONI, V. (Org.). Redefinições das fronteiras entre o público e o privado: implicações para a democratização da educação. Brasília, DF: Liber Livro, 2013. p. 290-307.

ROCHA, D. J. F.; PESSANHA, M. S. Exame da efetividade das políticas públicas: o caso da educação infantil em Porto Alegre. Achados de Auditoria, Porto Alegre, n. 5, p. 34-35, jun. 2016.

ROSEMBERG, F. Organizações multilaterais, estado e políticas de educação infantil. Cadernos de Pesquisa, n. 115, p. 25-63, mar. 2002.

ROSEMBERG, F. Sísifo e a educação infantil brasileira. Pro-Posições, v. 14, n. 1, p. 177-194, jan./abr. 2003.

ROSEMBERG, F. Análise das discrepâncias entre as conceituações de educação infantil do INEP e do IBGE: sugestões e subsídios para uma maior e mais eficiente divulgação dos dados. In: ARTES, A.; UNBEHAUM, S. Escritos de Fúlvia Rosemberg. São Paulo: Cortez, 2015.

SANTOS, J. B. dos. O Fundeb e a educação infantil. Curitiba: Appris, 2015.

SOUZA, Â. R. A teoria da agenda globalmente estruturada para a educação e sua apropriação pela pesquisa em políticas educacionais. RBPAE, v. 32, n. 2, p. 463485, maio/ago. 2016.

SUSIN, M. O. A qualidade na educação infantil comunitária em Porto Alegre: estudo de caso em quatro creches conveniadas. 2009. Tese (Doutorado em Educação)-Universidade Federal do Rio Grande do Sul, Porto Alegre, 2009. 
SUSIN, M. O.; MONTANO, M. A educação Infantil no Brasil: direito de toda criança ainda em construção. In: PERONI, V. (Org.). Diálogos sobre as redefinições no papel do Estado e nas fronteiras entre o público e o privado na educação. São Leopoldo: Oikos, 2015. p. 72-88.

Recebido em: 07 de março de 2017 Aceito em: 07 de agosto de 2017

Endereço para correspondência: Avenida Paulo Gama, 110, Farroupilha, 90040-060, Porto Alegre, Rio Grande do Sul, Brasil; malurflores@gmail.com 